\title{
ENTREVISTAS PERIODÍSTICAS Y TEXTOS DECLARATIVOS: UN PROCEDIMIENTO DE ANÁLISIS Y RECUPERACIÓN DOCUMENTALES BASADO EN MODOS DE BÚSQUEDA PRONOMINAL
}

\section{Antonio García-Gutiérrez}

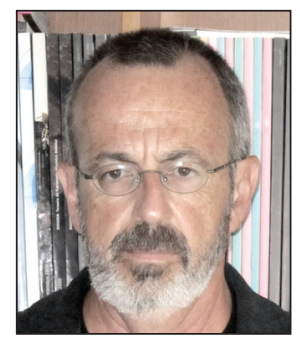

Antonio García-Gutiérrez es catedrático de la Universidad de Sevilla desde 1994 y, hasta esa fecha y desde 1980, fue profesor de documentación periodística y de análisis y lenguajes documentales en la Universidad Complutense de Madrid. Ha dirigido varios departamentos universitarios y ha sido durante años consultor de Unesco, interviniendo en proyectos documentales de organizaciones internacionales y españolas como la WTO, el Instituto Andaluz de Patrimonio Histórico o Asinel. Ha trabajado como evaluador de proyectos científicos del V Programa Marco de la CE y también ha sido durante varios años evaluador de profesorado universitario del área de ciencias sociales en agencias nacionales y autonómicas como Aneca y Agae. Autor de más de quince libros sobre documentación y organización del conocimiento y sobre memoria e identidad, estos últimos temas abordados desde la aproximación de los estudios culturales.

http://orcid.org/0000-0001-5217-2611

Universidad de Sevilla. Facultad de Comunicación Departamento de Periodismo 1 Américo Vespucio, s/n. 41092 Sevilla, España algarcia@us.es

\section{Resumen}

Se propone un procedimiento de análisis y recuperación de datos factuales a partir de entrevistas y textos declarativos periodísticos desde un enfoque pragmático. Los sistemas de documentación periodística suministran productos que no siempre responden a las demandas específicas de sus usuarios (periodistas, historiadores, profesores, investigadores sociales, público general), como ocurre con los llamados datos factuales. Para optimizar la obtención de este tipo de información puntual es necesario llevar a cabo estudios de los modos de interrogación pronominal (cómo se pide la información periodística) para convertirlos en categorías de análisis a través de las cuales los usuarios puedan ser simulados por los documentalistas de prensa. Sin embargo, estos estudios deben abarcar textos de un solo género periodístico, en este caso las entrevistas y lo que llamaremos "textos declarativos", ya que las condiciones y estructuras de cada género o tipo textual imponen procedimientos y reglas analíticas diferentes, a pesar de detectarse analogías y extrapolaciones que deben ser investigadas cautelosamente con el fin de obtener mayor precisión y adecuación en las respuestas del sistema documental.

\section{Palabras clave}

Documentación periodística, Información factual, Búsqueda pronominal, Entrevistas periodísticas, Declaraciones, Análisis documental, Recuperación documental.

Title: Journalistic interviews and statement texts: a procedure for information analysis and retrieval based on pronominal search modes

\section{Abstract}

This study proposes a pragmatic procedure of factual data analysis and retrieval of journalistic interviews and what we call "statement texts". Journalistic documentation systems do not always offer the precision required to meet the specific demands of their end-users (journalists, historians, teachers, social scientists, general audience), as is the case with factual data. The retrieval of fact-based information is optimized by determing how users will ask for these data, simulating their pronominal searching behaviour, and then transforming those search modes into analytical categories for use by press documentalists. However, such studies should focus on a specific journalistic genre (in this case interviews and "statement texts") because the conditions and structures of each genre or text type impose different analytical procedures and rules. Nonetheless, the resulting analogies and extrapolations should be carefully studied to improve the accuracy and relevance of the information system's search results.

\section{Keywords}

Journalistic documentation, Factual data, Pronominal search, Media interviews, Statement texts, Document analysis, Information retrieval. 
García-Gutiérrez, Antonio (2013). "Entrevistas periodísticas y textos declarativos: un procedimiento de análisis y recuperación documentales basado en modos de búsqueda pronominal". El profesional de la información, julio-agosto, v. 22 , n. 4, pp. 315-325.

http://dx.doi.org/10.3145/epi.2013.jul.07

\section{Introducción}

La digitalización de los archivos de prensa ha supuesto un gran avance en la obtención de información para periodistas, historiadores, investigadores sociales o público en general. La resolución tecnológica de antiguos problemas que acuciaban a la documentación periodística, fundamentalmente referidos a lagunas y déficits en las respuestas de los sistemas manuales o semiautomáticos ha venido acompañada, sin embargo, de problemas derivados de, justamente, lo contrario: una saturación de datos capaz de eclipsar la calidad de los mismos y un creciente abandono y pérdida de confianza de los usuarios.

Como en muchas aplicaciones de la documentación, en documentación periodística se ha producido una delegación de los objetos, objetivos y métodos de investigación al paradigma tecnicista, probablemente al considerar que la tecnología es una panacea que resuelve todos los problemas. Lejos de una posición tecnófoba, este trabajo pretende contribuir a un fructífero diálogo entre tecnología y discurso, asentado sobre el regreso a la documentación periodística y su patrimonio discursivo. Tal objeto de investigación tiene que ver con el análisis de contenido, la valoración y crítica de fuentes, la organización y la atención personal al usuario. Para ello, evidentemente, contando con la participación imprescindible de aplicaciones informáticas en algunas fases y para ciertos fines, siempre determinadas desde las necesidades de la documentación periodística y no al contrario.

No parece necesario insistir en que la llamada "exomemoria digital" ${ }^{\prime 1}$ que emerge del binomio información/tecnología, constituye uno de los recursos globales a partir del que nuestros sucesores entenderán las claves de existencia, sueños y expectativas de las sociedades actuales. Y un alto porcentaje de dicha memoria procede de los medios de comunicación. De esta toma de conciencia del futuro se desprende la universalidad y responsabilidad del trabajo desarrollado por los documentalistas de medios, rehabilitando y aplicando el sueño de Paul Otlet sobre las memorias registradas de lo actual y de lo cotidiano. De ahí que la investigación documental en el campo del periodismo haya de recuperar su dimensión discursiva y proponer reflexiones, teorías y estudios prácticos y específicos, como el que nos ocupa, para contribuir de manera consistente a la construcción de la memoria digital global.

Esta investigación se centra en el estudio de los modos de interrogación pronominal (pronombres interrogativos y derivados como: quién, a quién, con quién, sobre qué...) a través de los cuales los usuarios solicitan datos factuales (nombres, fechas, lugares, modos...) procedentes de un género informativo, la entrevista periodística ( $y$, parcialmente, de otros textos con declaraciones), y en cómo debe ser analizada, segmentada y organizada la información derivada de tales textos a fin de responder de forma precisa las deman- das efectuadas al sistema. El procedimiento -denominado pragmático por partir de los usos y efectos de la información-, forma parte de un programa de investigación más amplio que aborda los problemas del análisis y recuperación de la información factual de cada uno de los grandes géneros periodísticos informativos (noticias, reportajes, entrevistas) y de opinión (editoriales, columnas, críticas) con el fin de buscar una aproximación y homologación de las categorías operativas obtenidas -herramientas conceptuales usadas por los documentalistas- con un objetivo integrador a medio plazo.

A pesar de constituir una necesidad elemental, la búsqueda de datos factuales carece de precisión en los sistemas de documentación periodística

\section{Objetivos y aparato teórico-conceptual}

La documentación periodística debería obtenerse, al menos, en varios formatos de salida:

1) referencias hemerográficas con resúmenes, palabras clave e información catalográfica de los registros recogidos en una base de datos;

2) texto completo de noticias, artículos, entrevistas y otros géneros periodísticos;

3) datos factuales y derivados de comparaciones y verificaciones;

4) inferencias.

Los productos indicados en 1) y 2) son servidos habitualmente, con mayor o menor nivel de ruido, por los softwares de gestión documental (sgds). Las inferencias, procesos inductivos o deductivos a partir de una simulación del razonamiento de un experto humano llevada a cabo por una aplicación inteligente, precisan complejos estudios de equipos interdisciplinares en los que participen cognitivistas, analistas de contenido, especialistas en las materias (procesos judiciales, quiebras bancarias, diagnósticos médicos...) y, desde luego, tecnólogos. Restarían entonces los datos factuales: información puntual en torno a sujetos, lugares, fechas, consecuencias, antecedentes..., espectro de respuesta falto de precisión en los sistemas de documentación periodística, a pesar de constituir una de las necesidades elementales de búsqueda en esos sistemas.

En investigaciones previas (García-Gutiérrez, 1999) se abordó exclusivamente un análisis de noticias desde la sola perspectiva de sus condiciones de producción, a partir de una adaptación de la gramática de casos y de las aplicaciones que otros autores habían desarrollado en función de campos específicos de aplicación ${ }^{2}$ que, con el tiempo, se han re- 
velado parciales e insuficientes para abordar otros géneros, más allá de la noticia. La óptica de la producción aislada, sin tener en cuenta el destinatario final que da sentido a la totalidad del sistema ni el tratamiento global de los géneros periodísticos, tampoco se ha mostrado pertinente.

Para abordar el objeto señalado y culminar los objetivos propuestos, ha sido necesario trabajar con un conjunto de teorías, metodologías y conceptos instrumentales procedentes del análisis del discurso (Van-Dijk, 2001), el análisis automático del discurso (Pêcheux, 1978), la lingüística aplicada a la documentación (Cunha, 1990; García-Gutiérrez, 1999, Kobashi; Francelin, 2011; Ginez de Lara, 2011) y elementos proporcionados por la lingüística teórica (Fillmore, 1968) y estructural (Pottier, 1976). Del mismo modo, hemos utilizado parámetros de validación, particularmente los derivados de la "técnica de la mitad" (Krippendorf, 2002, -ver explicación más adelante-) a efectos de obtener un corpus de referencia empírico, así como las inferencias que se han realizado sobre construcciones de laboratorio -las macroproposiciones (MPs), explicadas más adelante-. Otras fuentes que nos han aclarado las propiedades "en origen" de la entrevista y textos declarativos a fin de tener en cuenta ciertas condiciones de producción que pudieran incidir en el proceso de formalización documental al que serán sometidos han sido Balsebre y Mateu, 1998; Martínez-Albertos, 2000; y Gomis, 2008. Naturalmente, se han tenido en cuenta otros trabajos marco sobre documentación periodística, además de varias contribuciones en un libro de investigación previo ya reseñado (1999) y, específicamente, las contribuciones de Fuentes-Pujol (1997) y Galdón (2002).

\section{Hipótesis de investigación}

Antes de proceder al desarrollo de la investigación, parece oportuno establecer la hipótesis general de partida, dividida en varias fases. Con objeto de satisfacer las búsquedas de tipo pronominal que los usuarios deberían poder efectuar en sistemas de documentación periodística para obtener datos factuales es necesario:

a) recoger y organizar las respuestas a estos modos de interrogación pronominal en macroproposiciones (MPs);

b) para ser operativas, las MPs deben ser articuladas en torno a la acción dominante "declarar";

c) los modos de interrogación pronominal son convertibles en categorías pragmáticas de análisis, segmentación y recuperación, a través de las MPs;

d) el conjunto del procedimiento otorga mayor fiabilidad y cientificidad al sistema documental al hacerse explicitable, reproducible y más comprobable por terceros, contribuyendo a reducir los niveles de subjetividad y opacidad habituales en los procesos analíticos de la documentación mediática.

Desglosando estos extremos, se revela necesario organizar y ejecutar las siguientes operaciones:

a) inventario teórico de modos de interrogación pronominal potencialmente relevantes en relación con las entrevistas y contenidos de los textos declarativos;

b) inventario de acciones sinónimas o cuasisinónimas del campo semántico de la acción "declarar" a partir de un análisis empírico de una muestra de entrevistas periodísticas y textos declarativos, así como de diccionarios y terminologías;

c) inventario pragmático de conectores con el fin de asignar y formalizar la segmentación de funciones conceptuales;

d) asociación de una categoría de análisis y de un segmento textual con cada modo de interrogación pronominal;

e) elaboración de MPs empíricas sobre los registros de la muestra y MPs ideales de laboratorio que contengan todas las funciones conceptuales posibles con el fin de facilitar el cotejo, la simulación y la homologación;

f) formalización de categorías y establecimiento de límites y alcance de las mismas;

g) señalar posibles extrapolaciones a géneros, discursos y campos con afinidad al objeto que centra esta investigación.

Una macroproposición (MP) es una síntesis de estructura canónica de las propuestas y elementos relevantes del texto, de acuerdo con los objetivos de su uso

En resumen, se trata de proponer un procedimiento de análisis de entrevistas y textos declarativos que, partiendo de una simulación sobre cómo pregunta un usuario-modelo, regule y explicite el modo cómo los documentalistas extraen los ejes significativos de tales textos. Esto debe ser así con el fin de ser convertidos en diferentes criterios de búsqueda (abandonando los habituales criterios no parametrizables como la intuición, la memoria o la experiencia), y también de propiciar una organización y búsqueda de la información basadas en roles o funciones conceptuales a partir de preguntas pronominales. De este modo se pueden reducir, o incluso anular en un alto porcentaje, las distorsiones de resultados que reciben los usuarios, adecuándolos a la información que solicitan. La aplicación del procedimiento ofrece dos mejoras inmediatas, ya obtenidas en el tratamiento de noticias (si bien parcialmente, desde la óptica de su producción):

- alta precisión y adecuación de las respuestas a las preguntas formuladas;

- posibilidad de revisión y control del análisis documental de contenidos periodísticos.

Finalmente, el procedimiento propuesto, restringido a entrevistas y textos declarativos en este trabajo, se incardina a un programa de investigación general que pretende dar cobertura a un conjunto de procedimientos de análisis y recuperación de datos factuales basado en modos de interrogación pronominal extensible a géneros informativos (noticia -ya finalizado-, reportaje -en ejecución- y entrevista) ${ }^{3}$ y de opinión (editorial, columna, crítica, entre otros). Las propuestas específicas que aquí se hagan no tienen sentido si no es como aportación a ese objetivo integrador más amplio. 


\section{Modos de interrogación pronominal de entrevistas y textos declarativos}

Antes de proceder a inventariar los modos de interrogación de nuestro usuario-modelo ${ }^{4}$, es necesario insistir en su restricción a un tipo discursivo particular, la entrevista periodística, sea publicada en un formato directo de preguntarespuesta o indirectamente como texto con declaraciones. Dicha restricción proporciona una solidez estructural que permite la comparación entre registros empíricos y, por tanto, la inducción del procedimiento. De la información provista exhaustivamente por un texto declarativo, un usuario modelo debe poder hacer grosso modo, e inicialmente ${ }^{5}$, los siguientes tipos de preguntas pronominales (partiendo del enunciador o entrevistado):

a) ¿quién dice? Se obtiene el sujeto entrevistado;

b) ¿qué dice o sobre qué? Se obtienen las respuestas relevantes macroetiquetadas;

c) ¿a quién lo dice? Se obtiene el nombre del entrevistador en su caso;

d) ¿por qué lo dice?

e) ¿para qué lo dice?

d) ¿qué consecuencias tiene decirlo?

f) ¿cómo lo dice?

g) ¿a través de qué lo dice?

h) ¿cuándo lo dice?

i) ¿dónde lo dice?

j) ¿en qué estado lo dice?

k) ¿con/contra quién lo dice?

Estos modos de interrogación, a falta de la depuración que será realizada más adelante, provienen de dos enfoques centrales de búsqueda: la persona entrevistada y cada una de sus declaraciones distintas y relevantes. El resto de preguntas arrastraría inicialmente una información de menor relevancia en términos documentales ${ }^{6}$, y tal vez de algún modo ya filtrada en las respuestas del entrevistado (la causa o fines de la entrevista, su estado anímico, el lugar o momento, etc.). En cualquier caso, estos modos de solicitar información deben corresponderse con protocolos de organización de la información en el sistema y, previamente, con una estrategia de interrogación o análisis a la que ha de ser sometido el texto por parte del documentalista en primera instancia ${ }^{7}$ con objeto de elaborar una MP.

\subsection{Corpus, registros y macroproposiciones (MPs)}

Aunque las entrevistas de prensa responden a un tipo textual sobradamente reconocible por su formato pregunta/ respuesta, los elementos debatidos en esta investigación también son válidos para otros textos organizados en torno a "declaraciones". En la amplia tipología de géneros periodísticos tradicionales, y en sus nuevas hibridaciones, puede detectarse una cierta transversalidad discursiva establecida por el carácter dominante de la acción declarativa, lo que nos permite concebir, construir y agrupar, a efectos estrictamente de análisis y organización documental, una diversidad de textos bajo la clasificación práctica de "textos declarativos". La característica común a todos ellos se- ría, justamente, la presencia de declaraciones, bien en el conocido formato de pregunta/respuesta, bien mediante la recogida de declaraciones literales o citadas indirectamente por los periodistas. Declaraciones que, incluso dentro de la misma unidad de contenido, pueden provenir de uno o más declarantes y tratar uno o más asuntos.

En definitiva, las consideraciones realizadas en este trabajo atañen a todo tipo de texto o subtexto periodístico cuya acción dominante sea la declaración (incluyendo, en su momento, los "totales"9 propios del audiovisual). Una rápida cuantificación sobre varios ejemplares de diarios, sin mayor alcance que la de calibrar su peso a ojo, nos lleva a estimar una presencia mayoritaria de los enunciados declarativos sobre los de otro tipo (reunión, ataque, venta, aumento...) en los géneros informativos periodísticos, por lo que practicamos un "vaciado" de tales géneros convencionales cuando sus contenidos son declaraciones, dedicándoles una investigación ad hoc como la presente, relegando a investigaciones simultáneas otros géneros informativos (noticias y reportajes) en torno a enunciados de acción (salvo, lógicamente, la "acción de decir"), tal es la hegemonía de las acciones en la lógica del procedimiento pragmático que se propone.

Para obtener los componentes del campo semántico de la acción "declarar" y generar inferencias por vía inductiva se procede, por un lado, a la constitución de un corpus experimental de referencia que recoge textos declarativos de géneros diversos (cuyas condiciones se exponen más adelante) y, por otro, por vía hipotético-deductiva, a la elaboración de MPs teóricas o ideales que confluyan con los resultados derivados de la vía empírica obteniéndose una retroalimentación de ambos itinerarios y una mayor consolidación de los resultados.

\subsection{Acciones declarativas}

Sobre lo que entendemos por acción declarativa, "declaraciones", debemos realizar dos operaciones de depuración: la primera relacionada con su polisemia y la segunda con su sinonimia. En cuanto a la polisemia, accidente semántico absolutamente perjudicial en los sistemas documentales (pues los términos afectados por ella dirigen simultáneamente a varios conceptos de escasa relación produciendo "ruido"), y en lo referente a declaraciones, deben descartarse los significados relacionados con proclamaciones oficiales colectivas en el sentido de manifiestos (derechos humanos y similares), testimonios judiciales o testificaciones policiales y, desde luego, declaraciones en otros aspectos lejanos a la propia verbalidad (de la renta, por ejemplo).

A efectos del procedimiento de análisis perseguido en este trabajo, entenderemos por declaraciones la explicación, exposición, afirmación, enunciación, confesión, revelación, información, testimonio ordinario, manifestación o comunicación, entre otra opciones, de cualquier asunto a los representantes directos (periodistas) o interpuestos (fuentes) de un medio de comunicación. Por tanto, si el texto recoge la declaración de un político imputado ante un juez, estará excluido del procedimiento de análisis de textos declarativos (y probablemente desviado a otro, por ser ya categorizado como enunciado de acción, que se ocupe de noticias o re- 
portajes) pero si "declara", incluso exactamente lo mismo, a un periodista, entrará bajo los protocolos analíticos propuestos. Incluso veremos cómo una causa, o cualquier otro rol conceptual relevante, expresada directamente por el declarante en su relato, adquiere una función distinta respecto al caso en que esa misma información no fuera ya expresada por el declarante sino inferida o relatada por el periodista (vid MP1 y MP2 en el epígrafe 5: Funciones conceptuales).

\section{Se trata de proponer un procedimiento} de análisis de entrevistas y textos declarativos que, partiendo de una simulación sobre cómo pregunta un usuariomodelo, regule y explicite el modo en que los documentalistas extraen los ejes significativos de tales textos

En cuanto al segundo accidente semántico, la sinonimia, como es sabido la multiplicidad de términos que se refieren a una misma noción no es perjudicial para los sistemas documentales, siempre que estén todas ellas recogidas en el sistema, de otro modo se genera "silencio". Sinónimos de declarar, en el sentido unisémico establecido, pueden ser todos los vocablos expuestos más arriba (explicar, exponer...) y muchos otros en la misma línea sémica: decir, hablar, indicar, responder, contestar, dar una conferencia, exponer, insistir, proferir, comentar, aseverar, matizar, detallar, apuntar, replicar, y otras formas más indirectas en el mismo sentido como: dirigirse a, denunciar, apreciar, estimar..., e incluso declaraciones negativas: rechazar, negar, desautorizar..., y ausencia absoluta de declaración: silenciar, omitir, callar (siempre con la restricción de que se "declare" a los medios, es decir, a través de una "massmediación").

Para agotar todas las entradas del corpus de referencia, de acuerdo con lo establecido en la metodología de validación denominada "técnica de la mitad" (Krippendorf, 2002), se procedió a consultar simultáneamente dos muestras de tamaño idéntico de modo que el alcance de los umbrales de repetición de enunciados declarativos en ambas muestras aportaran la fiabilidad de haber obtenido un inventario de sinónimos suficiente. De esta operaciones comparadas se obtuvo un listado de más de 70 formas de sinonimia directa o indirecta de "declarar", encontradas a partir de las dos muestras de 200 textos declarativos cada una (entrevistas o noticias organizadas en torno a declaraciones) rastreados en MyNews, tres periódicos y dos revistas nacionales de información general ${ }^{8}$. Finalmente el primer inventario, de procedencia empírica, fue enriquecido por entradas de los diccionarios de la RAE, WordReference.com y Larousse, en este caso utilizados con objetivos deductivos. Como resultado parcial de este trabajo puede adelantarse que en un potencial sistema documental en el que fuera aplicado el procedimiento propuesto, todos los textos periodísticos urdidos en torno a declaraciones pueden ser analizados a partir de la acción "declarar". Esta expresión garantiza una optimización del método en función de los modos de interrogación pronominal expuestos más arriba, y una eficien- cia máxima del motor de búsqueda (y eventualmente de una aplicación de análisis automático) siempre que cuente con un módulo en el que las diferentes acciones sinónimas localizadas queden controladas y vinculadas en un campo semántico.

Mención especial debe hacerse respecto a un cuasi-sinónimo de declaración: entrevista. En términos documentales, un cuasi-sinónimo es un sinónimo forzado a partir de unas condiciones particulares, en este caso basadas en modos de interrogación y usuario-modelo. Quienes buscan entrevistas están más interesados en los sujetos que hacen las declaraciones y en los asuntos que relatan, que en la "modalidad" a través de la cual lo hacen, sea una entrevista propiamente dicha, rueda de prensa, totales ${ }^{9}$ o conferencia de prensa. Seleccionando la acción "declarar", la entrevista o los otros modos de declaración aparecerían como categorías dependientes de esa acción (lo mismo que el medio), situando al declarante como sujeto más relevante del texto y no al periodista (cuya relevancia sería activada si empleamos la acción "entrevistar"). El periodista, productor del texto de declaraciones, tiene un lugar reservado en el sistema documental, justamente el de autor, pero inicialmente no debe formar parte del análisis de contenido de las declaraciones (como ocurriría con la acción "entrevistar"). Para ello, la elección de la acción "declarar" destaca al declarante como sujeto, reubica al periodista como autor (en un campo de la descripción externa) y, especialmente, permite recopilar

\begin{tabular}{|c|c|}
\hline a & $\begin{array}{l}\text { Uso dativo, introduce al Paciente (ver epígrafe } \\
5 \text {, punto 2) en el caso de la acción "entrevistar". } \\
\text { Inaplicable en la acción "declarar }\end{array}$ \\
\hline sobre & $\begin{array}{l}\text { Afecta a los contenidos de la declaración. } \\
\text { Segmenta y diferencia cada uno de los subtemas } \\
\text { sobre los que habla el declarante. Se trata del co- } \\
\text { nector principal del procedimiento de análisis y } \\
\text { recuperación de entrevistas y textos declarativos }\end{array}$ \\
\hline mediante & $\begin{array}{l}\text { Introduce el modo no tangible, la estrategia o el } \\
\text { género discursivo de la declaración }\end{array}$ \\
\hline a través de & Introduce instrumentos o medios tangibles \\
\hline a causa de & $\begin{array}{l}\text { Introduce causas (motivaciones directas de la } \\
\text { declaración). Para diferenciar antecedentes y } \\
\text { contextualizadores, deben usarse llamadas o } \\
\text { siglas que determinen estas circunstancias como } \\
\text { atc o ctx (vid epígrafe 5, puntos } 11 \text { y 12) }\end{array}$ \\
\hline con el fin de & $\begin{array}{l}\text { Introduce las intenciones explícitas de la decla- } \\
\text { ración }\end{array}$ \\
\hline $\begin{array}{l}\text { en/como conse- } \\
\text { cuencia }\end{array}$ & $\begin{array}{l}\text { Introduce los efectos producidos, y efectivamen- } \\
\text { te constatados, por la declaración }\end{array}$ \\
\hline en & Introduce el lugar \\
\hline $\begin{array}{l}\text { desde, hasta, } \\
\text { durante }\end{array}$ & $\begin{array}{l}\text { Introducen temporalidad. En el caso de fechas } \\
\text { en las que se ejecuta la acción no se utilizará el } \\
\text { conector "en" (en marzo, en 2013, etc.) evitan- } \\
\text { do confusión con su función locativa (vid esta } \\
\text { salvedad en epígrafe 5, punto 10) y éstas irán } \\
\text { ubicadas tras la acción }\end{array}$ \\
\hline con/contra & Introduce asociación, apoyo o antagonismo \\
\hline $\begin{array}{l}\text { posición, comas } \\
\text { y otros señaliza- } \\
\text { dores convencio- } \\
\text { nales de función }\end{array}$ & $\begin{array}{l}\text { Aunque no son conectores propiamente dichos, } \\
\text { su rol es señalar una función conceptual en la } \\
\text { MP. Sus formas y límites se explicitan junto a las } \\
\text { categorías de análisis en el epígrafe } 5\end{array}$ \\
\hline
\end{tabular}

Tabla 1. Conectores sinónimos preferentes y su efecto 
y organizar lo declarado en un mismo campo de contenido preparado para responder a la pregunta pronominal ¿qué declara $X$ ?

Indudablemente si el usuario quiere conocer la modalidad de la declaración (entrevista, test, rueda de prensa...) le bastaría con preguntar ¿cómo declara? para que el sistema buscara el dato factual en el campo correspondiente. Sin embargo, "entrevistar" puede presentar algunos usos que obligan a recuperarla como acción dominante anulándose el rol modal que le hemos asignado. Cuando es noticia el mero hecho de que alguien ajeno a los medios realice la entrevista a otro personaje, o casos de similar excepcionalidad (por ejemplo, una supuesta entrevista de Almodóvar a Amenábar, de Bardem a Cruz, etc.) acciones como "entrevistar" e, incluso "conversar" (que reservaremos, en último lugar, para entrevistas en las que prime la reciprocidad), pueden eclipsar el papel preponderante y mayoritario de "declarar".

\subsection{Conectores}

Los conectores son construcciones léxicas desprovistas de significado lleno pero de gran relevancia estructural (por, en relación a, mediante, como, sobre, desde...) por la capacidad que tienen de introducir funciones conceptuales (en las lenguas declinadas, como se sabe, el conector es incorporado por los casos como el dativo, genitivo, etc.). A pesar de que los trabajos precursores de Pêcheux (1978) aportan un exhaustivo repertorio de conectores con el objetivo de proporcionar las bases de un análisis automático del discurso, su eficacia es relativa a efectos de esta investigación, requerida de grandes dosis de aplicación y formalización, si bien sus cuadros y categorizaciones de "conectivas" inspiran en gran medida nuestra aproximación y logros.

A partir del análisis empírico de la misma muestra de entrevistas y textos declarativos se elabora un extenso listado de conectores que es reducido, siguiendo el mismo procedimiento arbitrado para las acciones:

1으 mediante la detección de polisemias, procediéndose a:

- apagar los significados irrelevantes de las mismas en función de nuestros textos y objetivos;

- adjudicar un significado único.

2) mediante la aglutinación de sinónimos en cajas estancas, seleccionando, por mera convención, el más amplio y práctico entre ellos para representar a los demás ${ }^{10}$.

Como resultado de estas operaciones se obtuvo una lista convencional de sinónimos preferentes con objeto de ser aplicados en la articulación de ejes significativos y funciones conceptuales de las MPs (tabla 1 ).

\subsection{Construcción de registros. Macroproposiciones}

El documentalista de prensa opera con texto libre (el producido por los periodistas) pero éste no permite sistematizar y formalizar el trabajo documental, lo que plantea un efecto nocivo sobre sus indicadores de cientificidad, esto es, sobre sus niveles de explicitación, verificación e incluso reproducción por terceros. A efectos de investigación, el texto libre tampoco es recomendable como unidad de observación dada la dispersión y lenguaje retórico propios del discurso periodístico ${ }^{11}$, obstáculos que sugieren la construcción de "observables" que llamaremos macroproposiciones en el sentido de Van-Dijk (2001). Las MPs, junto a otros datos necesarios, constituirán los registros o unidades de observación de la muestra de laboratorio.

La MP consiste en una síntesis de estructura canónica de las propuestas y elementos relevantes del texto, de acuerdo con los objetivos de su uso. En este caso, el sentido de las MPs, en primera instancia, es la constitución de unidades "observables" que sirvan para detectar problemas y proponer soluciones en relación con un procedimiento de análisis y recuperación de textos declarativos a partir de modos de interrogación pronominal. En segunda instancia, las MPs pueden operar como un marco textual controlable que proporcione fiabilidad y homologación a los protocolos de análisis y representación manejados por el profesional de la información. En última instancia, ofrecen una plataforma de alto nivel de formalización para analizadores automáticos que apoyen el trabajo masivo, y movido por la urgencia, desarrollado por los documentalistas de medios ${ }^{12}$.

Como "observable" de investigación, las MPs se presentan mediante estructuras estables articuladas en torno a una acción, en este caso, "declarar" (con las salvedades hechas sobre "entrevistar" o "conversar"), expresada en presente de indicativo, precedida de la respuesta a la pregunta pronominal ¿quién declara? A la acción le sucede un predicado en el que se ordenan fechas, lugares, asuntos sobre los que se declara... Este orden convencional implica función o rol, por tanto tiene una alta relevancia para el procedimiento, y será detallado más adelante. El registro de laboratorio adopta la apariencia siguiente:

\begin{tabular}{|l|l|}
\hline Descripción externa: & Código \\
\hline $\begin{array}{l}\text { Autor (apellidos, nombre): titulares. Publicación (medio). Fecha } \\
\text { (AAAAMMDD). Páginas. }\end{array}$ \\
\hline $\begin{array}{l}\text { Macroproposición: sujeto <--> acción <--> predicado (tiempo, lugar, } \\
\text { asuntos, modo...) }\end{array}$ \\
\hline Acciones sinónimas y cuasisinónimas: \\
\hline Conectores: \\
\hline $\begin{array}{l}\text { Descriptores (reservado a ulteriores ensayos sobre representación } \\
\text { documental) }\end{array}$ \\
\hline Observaciones: \\
\hline
\end{tabular}

A continuación procede abordar la discusión sobre la correspondencia entre modos de interrogación pronominal y categorías que ya han resultado efectivas en el análisis de noticias organizadas en torno a "enunciados de hacer" (atentar, prohibir, visitar...). Los "enunciados de decir", a pesar de constituir una modalidad de enunciados de hacer, son mayoritarios y, de hecho, noticias aparentemente construidas en torno a un enunciado de hacer, se desvelan en el último párrafo como textos de declaraciones, por lo que su procedimiento de análisis está más próximo del propuesto para entrevistas periodísticas que del arbitrado para noticias o reportajes. Como aportación argumental se elaboran en laboratorio varias MPs construidas sobre textos declarativos con datos ficticios pues su objetivo es la identificación 
de funciones conceptuales que se correspondan con modos de interrogación pronominal y éstos, a su vez, con categorías de análisis y recuperación con las que pueda operar el documentalista o una aplicación informática ad hoc, fase siguiente a esta investigación.

\section{Funciones conceptuales y discusión sobre límites de categorías de análisis}

A partir del establecimiento de la acción "declarar" como eje articulador de la MP, la circunstancia derivada del propio hecho de declarar, la declaración, constituye el punto central de búsqueda sobre el que el usuario realizará la interrogación pronominal (¿quién declara?, ¿qué declara?...) y, obedeciendo a reglas pragmáticas será también, por tanto, el punto central de análisis en el ejercicio de simulación del usuario llevado a cabo por el mediador-documentalista. Así, la acción declarar queda fuera del inventario de preguntas a la vez que lo preside. Esta decisiva convención, sin la cual no es posible aportar estabilidad, sistematicidad, explicitación, homologación, reproducción y verificación al procedimiento, impone algunas reconsideraciones sobre los modos de interrogación pronominal iniciales, obteniéndose un listado más definitivo asociado a categorías operativas inspiradas en la gramática de $\operatorname{casos}^{13}$ sobre las que también se apuntan comentarios respecto a sus límites y alcances:

Acción (a) ${ }^{14}$ : declarar (proceso representado por el sustantivo plural, declaraciones, para evitar formalmente alguna polisemia inicial). En los casos excepcionales en que el entrevistador sea en sí mismo noticia o personaje de actualidad, y no un profesional de los medios sin relevancia social, la acción elegida habría de ser entrevistar o conversar (si se trata de un diálogo de mayor intimidad). Sobre las opciones entrevistar / conversar / declarar se ejecutarán, entonces, los siguientes modos de interrogación pronominal:

1. ¿Quién? Se obtiene la categoría Agente (ag). El Agente es el entrevistador, si es personaje y no profesional de los medios. En el caso de que la acción sea declarar (la mayoría de los casos en el corpus) el Agente es el entrevistado.

2. ¿(A) quién? Paciente (p). De la acción entrevistar, se obtiene el nombre del entrevistador de excepción. La acción declarar dejaría este campo vacío, toda vez que el profesional no es objeto del contenido y ya aparece como autor en el correspondiente campo de descripción externa ( $c f r$. MP2 y MP3). Debe advertirse que este campo sí sería de obligada contestación si se dan otros valores polisémicos de declarar (ante el juez, a Hacienda, estado de emergencia, etc.), pero este tipo de enunciados corresponde, como se ha expuesto, a otro género textual -generalmente noticias en las que "declaración", ahora en singular, funciona como enunciado de hacer-y, por tanto, requiere otras normas procedimentales.

3. ¿(Sobre) qué? Objeto pasivo (obp). ¿Qué dice o sobre qué habla el entrevistado (ag)? Tras una búsqueda minuciosa por parte del documentalista en entrecomillados (si se trata de noticias con citas), o en el formato pregunta/respuesta (si se trata de cuestionarios y entrevistas periodísticas de todo rango), y ya con independencia de que la acción necesaria sea declarar, entrevistar, o conversar. No hay correspondencia entre número de temas declarados y número de preguntas/respuestas. De hecho, varias preguntas/respuestas pueden abordar un solo tema o en una sola respuesta se tratan varios temas desglosables en datos factuales (en el mismo párrafo habla de sus dos libros y los asocia a aficiones y proyectos...).

El documentalista ha de aplicar criterios cualitativos (novedad e interés son los más habituales) y cuantitativos de relevancia (el espacio dedicado o extensión sería el más decisivo) para extraer los temas tratados en las declaraciones. De un inventario en bruto de estos temas se obtienen etiquetas que han de ser transformadas en representaciones (palabras clave) aptas para la recuperación (preferentemente sustantivos y sintagmas nominales).

\section{Aplicaciones informáticas inteligentes} podrían relevar a los documentalistas de prensa de una gran cantidad de operaciones secundarias que pueden ser efectuadas a partir de MPs consistentes

En ningún caso es útil mantener frases literales, valoraciones o formas retóricas que sólo llevarían distorsión a la respuesta factual (el contenido esencial de la respuesta o posición) a menos que cada forma retórica esté informáticamente asociada a una forma descriptiva. En todo caso, en las MPs, las respuestas a la categoría objeto pasivo (obp) deben ser etiquetas descriptivas que suceden a la acción (no inmediatamente si existen datos factuales sobre lugar y tiempo) y van precedidas del conector "sobre" (X declara sobre obp1, sobre obp2, sobre obp3). El uso del conector "sobre" y la posición posverbal son esenciales a efectos de un posterior reconocimiento informático de los enunciados.

En el caso de juicio de valor expresado mediante calificativos o simples afirmaciones y negaciones (¿qué le parece el cine iraní?: muy bueno o excelente, o ¿le gusta el cine iraní?: sí) la representación se basará en sustantivos o sintagmas nominales genéricos que recojan las posiciones como: valoración positiva / valoración negativa / apoyo / rechazo, etc. ${ }^{15}$. Finalmente, hay tantos objetos pasivos como temas relevantes se hayan extraído de las declaraciones (obp1, obp2, obp3...). La formulación pronominal en la recuperación sería ¿qué declaraciones hace $X$ sobre obp1, obp2...? o incluso ¿qué declaraciones hay sobre obp2?

4. ¿Cómo? Modo (m). Normalmente género o modalidad, canal no tangible, a través del que es emitida la declaración: conferencia de prensa, rueda de prensa, mesa redonda..., pero también: gritando, con urgencia, a puerta cerrada, cautelosamente y otros muchos adverbios y categorías modales si prestan relevancia al texto. El conector modal sería convencionalmente "mediante" o un adverbio modal (con desinencia -mente).

5. ¿(A través de) qué? Instrumento (i). Generalmente empresa emisora o editora, siempre un medio tangible, a través del cual se emite la declaración exceptuando el medio que la publica y es objeto del análisis. Por ejemplo, El país publica total o parcialmente las declaraciones que ha hecho un 
personaje en Antena3TV. El instrumento sería Antena3TV pues El país, el medio en el que se publica la entrevista objeto del análisis, no forma parte del contenido y aparece (del mismo modo que el autor) en el campo publicación de la descripción externa. Si fuese relevante, el instrumento puede también referirse a tecnologías o medios de emisión de naturaleza distinta a las empresas de comunicación, como infraestructura (satélites, cables...) o aparatos relacionados con el audio (radio, televisor, altavoz, micro...). El conector instrumental normalizado sería "a través de".

6. ¿(Por) qué? Causa (c). Incluye la motivación que ha llevado al entrevistado (ag) a realizar la declaración (por ejemplo, reciente toma de posesión en un cargo, cien días de gobierno...). Muy habitualmente este tipo causal forma parte de lo declarado (obp) siendo que el orden de las categorías establece ya prioridad para la asignación de un concepto (lo que se dice tiene más importancia como declaración (obp) que como motivación de la declaración (c)). La categoría causal también puede referirse a antecedentes (atc) (ej.: cada año ofrece una entrevista o lo hizo hace cinco años) y a contextos (ctx) (ej.: la declaración la hace en el marco de la Seminci). El conector causal normalizado podría ser "a causa de" u otro asociado como sinónimo por el sistema.

7. ¿(Para) qué? Finalidad (f). Intención u objetivo de la declaración, generalmente revelado por el periodista en una entradilla o formando parte de un obp, como ocurre con las causas (por ej. "declara para concienciar a la sociedad"). El conector final sería "con el fin de" u otro sinónimo asociado por el sistema.

8. ¿(Con) qué (consecuencias)? Consecuencia (cc). Normalmente en una entrevista no aparecen aún las consecuencias o reacciones a la misma -a sus declaraciones- y el hecho de que el entrevistado mencione los posibles efectos, es decir, los incluya como obp, no indica el efecto mismo sino sólo una expectativa [por tanto adopta una función de objeto pasivo (obp)] si forma parte de lo declarado o de la finalidad (f), si no lo hace). El conector consecuencial sería "en/como consecuencia de" u otro sinónimo asociado por el sistema.

9. ¿Dónde? Lugar (I). Lugar en el que hace la declaración. Los lugares de los que habla en la declaración son obps. EI lugar en el que se publica la declaración forma parte de la descripción externa y no del análisis de contenido. La función conceptual I sólo se activa cuando ag no habla del lugar (si hablara sobre él sería obp) pero el texto o entradilla de algún modo lo menciona y tiene relevancia a pesar de no formar parte de lo declarado. El conector de lugar sería "en" seguido del nombre del lugar, tras el tiempo, en su caso, y el verbo.

10. ¿Cuándo? Tiempo (t). Fecha o periodo en el que hace la declaración. Las fechas o cronologías a las que hace referencia el entrevistado son obps. La fecha de publicación de la declaración forma parte de la descripción externa. El conector temporal es "en" seguido de fecha o sólo fecha tras el verbo, durante seguido de periodo, desde y hasta seguidos de fecha. La función conceptual t solo se activa en el mismo caso descrito en 9).

11. ¿(En) qué (situación está ag/p)? Situación (st). Se refiere al estado involuntario en el que se encuentran entrevistado (bajo presiones, eufórico, enfermo...) o entrevistador (con muy escasa frecuencia). La situación podría ser confundida, por un lado, con la causa (motivación), aunque la causa es lo que motiva a declarar y no el estado en el que se encuentra involuntariamente el declarante, aunque éste podría desencadenar un causativo. Ej.: la categorización es distinta si se está enfermo (st) cuando se declara, que si se declara a causa de la enfermedad (c). Por otro, la st tiende a confundirse con el modo de la declaración (aunque el modo es el género o un proceso voluntario que atañe a la acción y la situación es involuntaria y atañe al agente), pero habitualmente aparece formando parte de un obp cuando no es mencionado por el propio entrevistador. No hay conector explícito de situación salvo la posición en la MP: st se ubica entre el sujeto y el verbo, separada de ambos por comas (o entre verbo y el paciente, si lo hubiera y fuera afectado por st, separada de ambos por comas).

12. ¿(Con) quién (lo dice ag/p)? Asociativo (asc). Se trata de otros sujetos relacionados con el entrevistado, o entrevistador en raras ocurrencias, bien por apoyar, rechazar o en todo caso formar parte de controversias y debates. Puede provenir de un comentario del entrevistador, en cuyo caso se trata de un st o forma parte de la declaración, por tanto un obp. El conector de asociativo comienza por "con" sucede al agente y su situación si la hubiere. Igualmente sucede al paciente y su situación, si la hubiere. En ciertos casos podría confundirse con el agente mismo, pero entonces se trataría de otro protagonista de la declaración, un segundo agente 0 , en su caso, paciente, y no un mero acompañante.

Según lo expuesto y construyendo las MPS de acuerdo con el procedimiento pragmático, se observa que la acción y las dos primeras categorías (ag y obp, excepcionalmente también p) constituyen el núcleo fuerte de la relevancia de los textos declarativos y, por tanto, de los formatos de respuestas suministrados a los usuarios. Se observa también que las restantes categorías tienen menor relevancia y que singularmente de 6) a 12) (c, f, cc, l, t, st, asc) suelen formar parte de la declaración, por lo que pierden su independencia categorial y se incorporan como obps. En cuanto a la categoría 4) (modo) se comprueba que el género periodístico (o algún comentario modal como urgentemente, etc.) es suministrado por el periodista o por el propio contexto de publicación (sección, alusión, etc. ) pues los declarantes no hacen mención a las mismas, y respecto a 5) (instrumento, medio emisor del que se transcribe la declaración) aparece en escasas ocurrencias y en ninguna ocasión como obp. A continuación, y a efectos de clarificar los resultados y reglas de procedimiento, veamos varios ejemplos de macroproposiciones (MPs) artificiales exhaustivas ${ }^{16}$, con modificaciones deliberadamente introducidas en las funciones conceptuales st y asc de MP2 respecto a MP1 (en las que su comportamiento funcional es de obp al formar parte de las declaraciones) y su desestructuración categorial a tenor de los diversos modos de interrogación pronominal ${ }^{17}$ :

MP1 / El primer ministro X / declara / sobre la política económica del bienio 2013-2014 / , / sobre las presiones del líder opositor / , /sobre su agradecimiento al apoyo parlamentario que recibe / y / sobre el incremento de las relaciones comerciales y culturales con América Latina /. 
(a) declaraciones
¿Quién declara? <--> (ag) <--> primer ministro X
¿Sobre qué declara? <--> (obp1) <--> política económica / bienio 2013-2014
¿Sobre qué declara? <--> (obp2) <--> presión política / líder opositor
¿Sobre qué declara? <--> (obp3) <--> agradecimiento / apoyo parlamentario
¿Sobre qué declara? <--> (obp4) <--> incremento / re- laciones comerciales / relaciones culturales / América Latina

MP2 / El primer ministro XX / , / presionado por el líder opositor / , y / con apoyo del parlamento / , / declara / el / 12 de octubre de 2013 / en Lisboa / , / mediante rueda de prensa / y / a través del Canal20 / / sobre la política económica / del / bienio 2013-2014 / , / sobre el incremento de las relaciones comerciales y culturales con América Latina / , / a causa del resultado negativo en la balanza comercial / , / con el fin de tranquilizar a los mercados financieros / y / como consecuencia éstos ya han mostrado señales positivas /.

(a) declaraciones

¿Quién? <--> (ag) <--> primer ministro XX

¿En qué situación? <--> st <--> presionado / líder opositor

¿Con quién? <--> asc <--> apoyo / parlamento

¿Sobre qué declara? <--> (obp1) <--> política económica / bienio 2013-2014

¿Sobre qué declara? (obp2) incremento / relaciones comerciales / relaciones culturales / América Latina

¿Cómo? <--> $(\mathrm{m})<-->$ rueda de prensa

¿A través de qué? <--> (i) <--> Canal20

¿Por qué? <--> (c) <--> resultado negativo / balanza comercial

¿Para qué? <--> (f) <--> tranquilidad / mercados financieros

¿Qué consecuencias? <--> (cc) <--> señales positivas / mercados financieros

$$
\begin{aligned}
& \text { ¿Dónde? <--> (I) <--> Lisboa } \\
& \text { ¿Cuándo? <--> (t) <--> bienio 2013-2014 }
\end{aligned}
$$

Por último, veamos el comportamiento de la función conceptual de quién declara en el caso poco frecuente de las acciones entrevistar o conversar:

MP3 El / actor A / entrevista / al / futbolista F / sobre sus premios deportivos / y / sobre su fichaje en el equipo $E$ /...

(a) entrevista

$$
\begin{aligned}
& \text { ¿Quién entrevista? <--> }(\mathrm{ag})<-->\text { actor } A \\
& \text { ¿A quién entrevista? <-->(p) <--> futbolista F } \\
& \text { ¿Sobre qué entrevista? <--> (obp1) <--> premios depor- } \\
& \text { tivos } \\
& \text { ¿Sobre qué entrevista? <--> (obp2) <--> fichaje / equipo E }
\end{aligned}
$$

MP4 / El actor A / y / el futbolista F / conversan / sobre su amistad desde la infancia / y / sobre... (a) conversación

$$
\begin{aligned}
& \text { ¿Quién conversa? <--> (ag) <--> actor A / futbolista F } \\
& \text { ¿Sobre qué conversa? <--> (obp) <--> amistad / infancia } \\
& \text { / etc. }
\end{aligned}
$$

\section{Conclusiones}

A través de la elaboración de macroproposiciones (MPs), tanto sobre registros empíricos como de raíz teórica, se comprueba la correspondencia de datos factuales y modos de interrogación pronominal efectuados por usuarios, mediante un análisis categorial homologable y explicitable y que puede contar con convenciones simples para un uso sencillo e intuitivo por parte del documentalista. En todo caso el módulo de recuperación debe ser asistido por uno de los tantos sistemas de gestión de bases de datos -o por sistemas expertos evolucionados- existentes en el mercado informático o producidos ex profeso, en una fase posterior del presente programa de investigación, muy probablemente, modificando pautas y convenciones aquí propuestas pero con efectos irrelevantes sobre el modelo categorial. Se constata la necesidad y viabilidad de construir MPs desde ambos enfoques, y de hacerlo sistemática e intensivamente de cara a la informatización completa y futura del procedimiento para contar con una amplia base casuística.

En tanto que las MPs empíricas han aportado solidez inductiva para modelizar acciones y conectores, las MPs teóricas han permitido cotejar integralmente todas las funciones conceptuales logrando deducciones relevantes para enriquecer el procedimiento. Se verifica que la precisión puede llevarse a niveles mayores de lo esperado, como queda evidenciado en el deliberado intercambio de funciones conceptuales usado en MP1 y MP2: en MP1, el hecho de declarar sobre "las presiones del líder opositor", así como sobre el "agradecimiento del primer ministro al apoyo parlamentario" forman parte de lo declarado (y se asignan a sendos obps) en tanto que la misma información, en la MP2, no es declarada por el agente sino deducida o relatada por el periodista, de ahí que haya sido asignada a las categorías situación (st) y asociativo (asc). El minucioso trabajo de los documentalistas de prensa, y el tiempo dedicado a elaborar MPs, centrado genuinamente con este procedimiento en aspectos discursivos y no meramente rutinarios, podría verse compensado a medio plazo -para empresas e instituciones documentales- por la actuación de aplicaciones informáticas inteligentes que relevaran a los documentalistas de una gran cantidad de operaciones secundarias que pueden ser efectuadas a partir de MPs consistentes, además de potenciar el rendimiento y satisfacción de los usuarios por la capacidad de respuesta del sistema. A largo plazo la automatización del sistema podría ser casi completa aunque no contamos con evidencias que sustenten de modo irrefutable esta afirmación salvo por algunos avances observados en proyectos realizados en áreas de la traducción y la elaboración automática de resúmenes que, si bien comparten elementos con la documentación periodística, sus objetos, discursos, usos y objetivos difieren en gran medida.

Queda verificada la hipótesis de partida, tanto en sus términos generales como en sus desarrollos particulares, siempre que el procedimiento se sujete a convenciones y parta 
de una macroproposición con acción y conectores formalizados. La acción "declarar" se muestra como la más ampliamente representada de su campo semántico al recoger mayoritariamente los significados de los verbos dominantes en el corpus de entrevistas y textos declarativos (decir, señalar, apuntar, relatar, responder, añadir, advertir, etc.), de acuerdo con lo argumentado en el epígrafe 4.2, pero es necesario reservar dos acciones normalizadas (entrevistar y conversar) para satisfacer el análisis de ciertos textos, también declarativos, aunque de escasa frecuencia. Estas dos acciones implican algunas variantes específicas en el procedimiento tal como se muestra en los ejemplos del punto 5 . Finalmente, se comprueba que las demandas pronominales son convertibles en categorías de análisis derivadas de un procedimiento pragmático y que, como se demuestra en los ejemplos, la totalidad del proceso analítico, habitualmente altamente subjetivo y opaco, se beneficia en términos de fiabilidad y cientificidad al hacerse más explícito, reproducible y comprobable por terceros.

\section{Aunque el procedimiento propuesto se ha basado en textos en castellano, sería extrapolable a lenguas próximas como catalán, gallego y portugués}

\section{Campos de investigación inmediatos y colaterales}

A continuación se indican temas que deben ser abordados en próximas investigaciones y algunas extrapolaciones posibles a raíz de las conclusiones obtenidas en este estudio:

- a pesar de que el procedimiento se ha comprobado sobre un género informativo, como la entrevista y los subtextos declarativos en general, la estabilidad que presenta la acción nuclear seleccionada sugiere diferencias no menores de procedimiento en relación con los otros géneros informativos (noticias y reportajes, sujetos a gran dispersión verbal de los enunciados "de hacer" dominantes) y, paradójicamente, mayores analogías estructurales respecto a los géneros de opinión debido a su mayor concentración y estabilidad en las acciones dominantes.

- el procedimiento propuesto se ha basado en textos en castellano. No obstante, es posible conjeturar un alto nivel de extrapolación en primera instancia, con las modificaciones que procedan, hacia lenguas muy próximas y derivadas del latín como catalán, gallego y portugués.

- la propuesta soluciona no sólo la falta de homologación entre documentalistas de prensa, en lo que se refiere a los resultados obtenidos en análisis y representación de textos declarativos, sino también entre docentes y estudiantes de documentación periodística, en general ajenos a las metodologías de análisis de contenido, como la aquí propuesta, y que contribuyen a objetivar la obtención de resultados en la formación y ejercicio profesional.

- el procedimiento resuelve una fase fundamental del análisis de contenido y de la recuperación de datos factuales procedentes de textos declarativos en documentación periodística escrita cualquiera que sea el medio de difusión (prensa, radio o televisión) pero, igualmente, plantea las bases para la solución a la problemática derivada de entrevistas y totales ${ }^{9}$ propiamente audiovisuales si se introducen las oportunas adaptaciones metodológicas impuestas por la imagen y sonido.

\section{Notas}

1. El conjunto planetario de la memoria registrada en soporte electrónico. Concepto analizado en García-Gutiérrez (2004).

2. Fundamentalmente de la aún vigente teoría de Fillmore (1968) y de las aplicaciones de Isabel Cunha (1990) a efectos de clasificar los materiales de la historia colonial portuguesa.

3. La incidencia de las grandes tipologías convencionales de géneros periodísticos, a efectos de esta investigación, es mínima pues es necesario operar con constructos de laboratorio. Sólo a partir de esa base, los géneros irrumpen en el procedimiento de análisis con su idiosincrasia particular. Sobre la tipología de géneros, entre una amplia bibliografía, remitimos al clásico libro de Martínez-Albertos (2000) o al trabajo más heterodoxo de Gomis (2008). En cuanto a la entrevista, y por ser muy exhaustivo respecto a un objeto tan específico, remitimos a Balsebre y Mateu (1998).

4. Nos inspiramos en el concepto de lector-modelo de Eco (1990): también el documentalista de prensa elabora sus producciones, sus "textos", para usuarios-modelo, a los que debe prever en su organización del conocimiento con exhaustividad y precisión. Dado el conocimiento empírico generalizado sobre cómo se solicita la información factual -en este caso de entrevistas periodísticas y textos con declaraciones-, se ha contado con las aportaciones informales, que consideramos suficientes, de varios profesores de periodismo, periodistas y alumnos de periodismo. Se han observado e inventariado esos modos de pregunta pronominal, accediéndose inmediatamente a un umbral de repetición que no ha hecho necesario, por tanto, desarrollar complejos análisis de las necesidades de usuarios como los recomendados, para otras aplicaciones de la documentación y específicamente de la documentación científica, por el imprescindible y ya clásico libro de Sanz-Casado (1994).

5. Estos modos de interrogación habrán de ser matizados a lo largo del procedimiento.

6. Hablamos de una relevancia en términos de la organización de la información, esto es, en clave metodológica pues la relevancia temática, incluso de un detalle secundario e inadvertido sólo puede establecerla el usuario de acuerdo con nuestra posición pragmática.

7. No sólo no es descartable el reconocimiento de las estructuras textuales por parte de programas informáticos sino que ya existen numerosas herramientas digitales que podrían ser adiestradas y adaptadas a los usos de la documentación periodística hasta que lograran incorporar algoritmos y protocolos de interrogación textual automática simulando la lectura del documentalista de prensa (pero en todo caso asistidas en la fase de entrada). 
8. La mayor parte de las consultas de los medios online fue realizada sobre el catálogo Fama online (Pinterest) de la red de bibliotecas de la Universidad de Sevilla. La ascendencia ideológica o vinculaciones del medio a determinadas corporaciones o instituciones se estima que presentan una incidencia casi irrelevante a la hora del vaciado de acciones, conectores o estructuras ya que el uso de éstos está más determinado por el estilo, e incluso por la época, que por la ideología en sí. En cualquier caso, siendo ésta una primera aproximación, no debe descartarse un minucioso estudio posterior.

9. Totales. Recurso audiovisual en el que la parte más importante de la información es la banda de sonido. Corresponde habitualmente a declaraciones de personajes relevantes desde el punto de vista periodístico.

10. Recuérdese que la sinonimia no es perjudicial (todo lo contrario) en un sistema documental si están debidamente controlados y asociados los términos sinónimos. La convención aludida también fue determinada por un criterio estilístico: aquella forma que forzara menos los enunciados utilizados.

11. A pesar de contener claves discursivas, elementos, temáticas y apariencias que permiten hablar de géneros e incluso un reconocimiento empírico casi inmediato.

12. En el caso de lectura y segmentación automática de textos, el trabajo del documentalista se limitaría a la producción de macroproposiciones, una labor imprescindible que consiste en preparar metatextos de los contenidos periodísticos en formatos entendibles por aplicaciones informáticas y cuya investigación forma parte de una fase posterior de este mismo proyecto (que incluye todos los géneros y medios periodísticos). Una gigantesca base de conocimiento de estos metatextos asociados a sus textos de origen debería estar elaborada, sin embargo, antes de poder abordarse mínimamente la generación automática de MPs.

13. Vid los casos originales en Fillmore (1968) y adaptados a distintos discursos y fines en Cunha (1990) y García-Gutiérrez (1999).

14. La letra o sigla indicadora del operador de función es la misma que estamos utilizando en investigaciones simultáneas a ésta aplicadas a noticias y los diversos tipos de textos de opinión.

15. Aunque no se están abordando en esta investigación las opciones de representación, salvo en el caso ineludible de la acción por motivos estructurales, los conceptos derivados del análisis precisarían una urgente formalización en lenguaje controlado, incluyendo los de procedencia valorativa, de fuerte raigambre en los textos tratados aquí aunque, especialmente, en los géneros de opinión.

16. Las MPs de procedencia empírica cubren una media de 5 categorías aunque confirman la pertinencia del procedimiento y la consistencia de las categorías.

17. Los términos empleados aparecen en lenguaje libre y por tanto no es necesario reparar en su nivel de ambigüedad a falta de elaborar un lenguaje controlado de los mismos, innecesario a efectos de mostrar las funciones conceptuales a través de los ejemplos.

\section{Bibliografía}

Balsebre, Armand; Mateu, Manuel (1998). La entrevista en radio, televisión y prensa. Madrid: Cátedra, 432 pp. ISBN: 84 37616565

Cunha, Isabel (1990). Do mito à análise documentária. São Paulo: Edusp, 1990, 163 pp. ISBN: 8531400112

Eco, Umberto (1993). Lector in fabula. La cooperación interpretativa en el texto narrativo. Barcelona: Lumen, 330 pp. ISBN: 8426411428 http://goo.gl/THW1w

Fillmore, Charles J. (1968). "The case for case". En: Bach, Emmon; Harms, Robert T. (eds.). Universals in linguistic theory. New York: Holt Rinehart and Winston, pp. 1-88.

Fuentes-Pujol, Maria-Eulàlia (1997). Documentación y periodismo. Pamplona: Eunsa, 136 pp. ISBN: 8431315199

Galdón, Gabriel (coord.) (2002). Teoría y práctica de la documentación informativa. Barcelona: Ariel, 320 pp. ISBN: 84 34412934

García-Gutiérrez, Antonio (ed.) (1999). Introducción a la documentación informativa y periodística. Sevilla: Mad, 1999, 504 pp. ISBN: 8483114607

García-Gutiérrez, Antonio (2004). Otra memoria es posible. Estrategias descolonizadoras del archivo mundial. Buenos Aires: La Crujía, 204 pp. ISBN: 9871004540

Gomis, Llorenç (2008). Teoría de los géneros periodísticos. Barcelona: UOC Press. 218 p. ISBN: 9788497887014

Kobashi, Nair-Yumiko; Francelin, Marivalde-Moacir (2011). "Conceitos, categorias e organização do conhecimento". Informação \& informação, v. 16, n. 2, pp. 1-24.

http://www.uel.br/revistas/uel/index.php/informacao/ article/view/10390

Krippendorf, Klaus (2002). Metodología de análisis de contenido. Barcelona: Paidós, 270 pp. ISBN: 8475096271

Ginez de Lara, Marilda-Lopes (2011). "Conceitos de organização e representação do conhecimento na ótica das reflexões do Grupo Temma". Informação \& informação, v. 16, n. 2, pp. 92-121.

http://www.uel.br/revistas/uel/index.php/informacao/ article/view/10391

Martínez-Albertos, José-Luis (2000). Curso general de redacción periodística. Madrid: Paraninfo, 600 pp. ISBN: 84 28319286

Pêcheux, Michel (1978). Hacia el análisis automático del discurso. Madrid: Gredos, 269 pp. ISBN: 8424907728

Pottier, Bernard (1976). Lingüística general. Teoría y descripción. Madrid: Gredos, 426 pp. ISBN: 8424906853

Sanz-Casado, Elías (1994). Manual de estudios de usuarios. Madrid: Fundación Germán Sánchez Ruipérez, 288 pp. ISBN: 8486168937

Van-Dijk, Teun A. (2001). La noticia como discurso. Barcelona: Paidós, 288 pp. ISBN: 8475096220 